\title{
Down to Earth: History and philosophy of geoscience in practice for undergraduate education
}

\author{
Maarten G. Kleinhans ${ }^{1}$ D
}

Received: 7 January 2021 / Accepted: 11 July 2021 / Published online: 29 July 2021

(c) The Author(s) 2021

\begin{abstract}
Undergraduate geoscience students are rarely exposed to history and philosophy of science (HPS). I will describe the experiences with a short course unfavourably placed in the first year of a bachelor of earth science. Arguments how HPS could enrich their education in many ways are sketched. One useful didactic approach is to develop a broader interest by connecting HPS themes to practical cases throughout the curriculum, and develop learning activities that allow students to reflect on their skills, methods and their field in relation to other disciplines and interactions with society with abilities gained through exposure to HPS. Given support of the teaching staff, the tenets of philosophy of science in practice, of conceptual history of knowledge, and of ethics of science for society can fruitfully and directly be connected to the existing curriculum. This is ideally followed by a capstone HPS course late in the bachelor programme.
\end{abstract}

\section{The science of the Earth needs introductions}

Philosophy and history of science are arguably as relevant to students of geoscience as to students of other sciences (e.g. Grüne-Yanoff, 2014 provides arguments for this), but educating this target group poses a specific mixture of philosophical, historical and didactic challenges. This reflection paper briefly introduces the field of Geoscience, and outlines the challenges, examples of learning activities that worked, and suggestions to implement HPS durably into undergraduate earth science education.

Geoscience, or earth science, is a large connectome of natural science disciplines that study the Earth and other planets. Earth scientists study causes and effects of processes and mechanisms that range over spatiotemporal scales from, e.g., clay particles and molecular dynamics to planetary evolution over billions of years.

Maarten G. Kleinhans

m.g.kleinhans@uu.nl

1 Faculty of Geosciences, Department of Physical Geography, Universiteit Utrecht, Utrecht, The Netherlands 
The geosciences make use of physics, chemistry and biology and there is considerable overlap with civil engineering and ecosystem science. Philosophical literature on earth-scientific issues usually refers to geology, the reconstruction of Earth's past from the rock record, or to plate tectonics as a putative example of a scientific revolution. On the other hand, climatology and oceanography are usually considered branches of physics, but are also the core business of earth system science. Likewise, hydrology and (bio)geomorphology are important branches of the geosciences. The multi-faceted nature of the field is illustrated by the organization and sections in the European Geosciences Union (EGU), which has large annual conferences with in the order of 10,000 attendants. The EGU has 22 scientific divisions (https://www.egu.eu/structure/divisions/) that represent all disciplines in the geosciences: atmospheric sciences; biogeosciences; climate (past, present and future); cryospheric sciences; Earth magnetism and rock physics; energy, resources and the environment; Earth and space science informatics; geodesy; geodynamics; geosciences instrumentation and data systems; geomorphology; geochemistry, mineralogy, petrology and volcanology; hydrological sciences; natural hazards; nonlinear processes in geosciences; ocean sciences; planetary and solar system sciences; seismology; stratigraphy, sedimentology and palaeontology; soil system sciences; solarterrestrial sciences; tectonics and structural geology. A glance at the divisions in the European Physical Society (EPS) and the European Chemical Society (ECS) shows considerable overlap in themes with the EGU.

With the disciplinary breadth of the geosciences comes a great diversity of methodologies and epistemic practices. Historical science and experimental science are often contrasted (Currie, 2018) and some disciplines are indeed historical in that the development of Earth over a part or its entire period of existence is reconstructed (Baker, 1996; Kleinhans et al., 2005). Yet, at least half of the earth-scientific disciplines focus entirely on inference of causal laws and of causes of specific phenomena, or methods and technology to accomplish this, and use that knowledge for explanations and predictions through application of physics, chemistry and biology and through data analyses of present and past observables, experimentation, simulation, and combinations thereof (Currie, 2018; Gramelsberger et al., 2020; Kleinhans et al., 2010). The practice, as visible at EGU, shows frequent interactions and intermingling of experimental and historic approaches. One reason is that complex earth systems have some memory in the sense that the internal structure is preserved and its state is to some degree contingent on past conditions. Geoscientists gain understanding of system properties and dynamics, such as feedbacks, path-dependence, downward causation and tipping points, that are not meaningful from the perspective of classic linear causal relationships between a few variables (e.g. Ladyman et al., 2013; Parker, 2014). The notion of system is central to earth science and raises philosophical questions about emergence, holism and reductionism, about thermodynamics, complexity and the nature of life, geo-engineering and the controversial Gaia theory.

For philosophy and history of science, this great diversity of themes, methodologies, histories and connections to the other sciences, and the relevance in society, can be a mer à boire. However, the vast majority of philosophical and historical publications in journals and books are about physics, biology and chemistry. Admittedly, 
the membership numbers of EPS and ECS are about five to ten times higher than that of the EGU, but it seems to me that the geosciences are underrepresented. Historical and philosophical studies touch a few of the disciplines, notably historical disciplines such as geology where it concerns plate tectonics and palaeontology, and particularly the Cretaceous-Paleogene extinction well-known for the demise of the non-avian dinosaurs (e.g. Rappaport, 2008 and Rudwick, 2014 for history of geology; e.g. Currie, 2018 for philosophy). Numerous studies exist of climate science (e.g. Parker, 2014), but whether this falls under physics or geosciences is in part a semantic discussion and in part a history of the emergence of disciplines. Most of the other geoscientific disciplines and methodologies have not been the focus of HPS studies.

No unrequited love is lost. In earth science curricula, philosophy is rarely to be found. Why not, is unclear. To be sure, students can elect HPS courses and HPS minors, and in some programmes a course in ethics, philosophy or theology is compulsory, but to the best of my knowledge, geoscientific courses that refer to HPS issues are rare, except in curricula of sustainability science. Unawareness is one likely reason, and a disconnect between the practice and the philosophies of science in the previous century is perhaps another. As Baker (1996) states, "much of conventional analytical philosophy of science, which is based on the exemplar of experimental physics, fails to portray important aspects of geomorphological reasoning." (also see Cleland, 2001 and Dodick \& Dolphin, 2013). All earth science curricula and all undergraduate textbooks that I have studied over the past decade suggest widespread ignorance about what can be gained by HPS. Some sustainability science curricula have successfully incorporated social science, ethics and philosophy of science, but some earth science curricula are worried that this comes at the cost of loss of depth in the natural science. What with the competition for time in the curriculum with disciplinary and technical courses, which students and staff consider valuable for science and for employability on the job market, the unawareness is perpetuated. The result is highly trained professional earth scientists with little conceptual apparatus to analyse, and reflect on, the science and the interactions with society (e.g. Bierman, 2021; Dodick \& Dolphin, 2013). Put succinctly by an alumnus with a PhD now working in industry, who would like to see a broader training: "earth scientists have one tool for everything: for problem-solving, for innovation, for collaboration, for resolving conflicts, and for splitting rocks: the geological hammer". At best, the hammer is seasoned by folk wisdom peppered through the classes and field courses, such as "the present is the key to the past", perhaps with a simplistic summary on uniformitarianism versus catastrophism (see Baker, 1998).

\section{What would geoscience education gain from HPS?}

The section title is in part a rethorical question. Others have eloquently argued that teaching history and philosophy of science to science students increases their capacities and abilities and makes them better scientists (e.g. Grüne-Yanoff, 2014; Matthews, 2018). There is no reason why this would be different for geoscience. I can think of no reason why philosophy and geoscience would not benefit from more 
interchange. Below I argue what can be gained by integration of HPS in geoscience curricula, but there is much more relevant and useful HPS literature available than can be cited here.

Many classic topics in HPS are relevant for the geosciences as already illustrated earlier. Scientific debates on modelling and big data science (sometimes peppered with the derogatory "there are lies, big lies and statistics", or "all models are wrong, but some are useful") would benefit from the philosophical discourse on the complementarity of mechanistic and statistical causation (e.g. Illari \& Russo, 2014). More in general, the choice and justification of methods are often not analysed but simply accepted from habit and convention for lack of interest and time, even though they are the fundament under the scientific claims. The science would benefit from a better understanding of the history, justification and criticisms of methods and would benefit from the critical reflection on the scientific claims made on the basis of the methods. Such analysis requires abilities gained in HPS education (also see GrüneYanoff, 2014).

Within the geosciences, history is sometimes oversimplified. For example, undergraduate textbooks have boxes to tell tales about some discovery or past controversy. For these to be educational, students need to learn how knowledge increases, how controversies are resolved and how old hypotheses are sometimes revived (e.g. Baker, 1996, 1998). This requires lecturers to be aware of how and why their basic knowledge concepts have historically changed (Koselleck, 2002). This would also benefit scientists who sometimes present historic progress as simplistically cumulative or as Kuhnian revolutions made by heroes (e.g. Schellnhuber, 1999; Steffen et al., 2020), but perhaps missed the implications about scientific progress. In contrast, many students start the bachelor with a naive realism and tell us, when challenged to provide arguments for, or against a societally relevant subject, that science, and the lecturers, should be 'objective', and they could develop more nuanced positions if they knew that the notion of objectivity developed only recently and was not always a central value of science (Daston \& Galison, 2007). Also amongst geoscientific staff there is sometimes debate, often in relation to the climate crisis, about values in science. Perhaps this attitude of 'we stick to facts only' evolved on ideas of some philosophers of the previous century, who maintained a position of valuefree evaluation and acceptance of science, but the reasons why this position is no longer thought defendable (Gailbraith, 2021; Resnik \& Elliott, 2019) are important for science-policy interactions and can be understood with abilities gained in HPS education.

The links between science and society are strong and plentiful: earth scientists contribute to several of the UN sustainable development goals (Gill \& Smith, 2021). Geoscience students need to develop the skills to creatively utilize sound science knowledge in everyday life and in their professional career, the abilities to solve problems, make decisions and contribute to improving the quality of life (Bierman, 2021; Holbrook \& Rannikmae, 2007). Consequently, alumni must have acquired not only knowledge of the results of science, but also insight into the workings and limits of science from causation to interdisciplinary collaboration (Boon \& van Baalen, 2019; Dodick \& Dolphin, 2013). This will strengthen their science and their impact. They also need to be able to earn public trust in a critical and oftentimes skeptical 
societal setting, and listen to non-experts, involved public and other stakeholders about their informal and sometimes misconceived comprehension of the geoscientific issues to uncover their concerns (Stewart \& Lewis, 2017). The teaching of this is entirely left to the practitioners of science who, to put it somewhat provocatively, have little to no training in philosophy, history and ethics of science.

A naive attempt to enlighten the first-years would be to offer a course of History and Philosophy of Science (e.g. Eflin et al., 1999; Grüne-Yanoff, 2014; Machamer, 1998) and leave it at that. This misses the mark in two ways. First, students often have a different focus: the motivation and interests which made them choose to study earth science, and the entry requirements for later courses.Students consider earth science and technical skills of immediate importance for their bachelor and future job prospects. Second, if the usefulness of HPS for geoscience remains unclear to students or if HPS topics are never referred to later in the bachelor by lecturers, it doesn't stick. This, combined with the competition for precious time in the curriculum, has been reason enough for earth science educators to oppose a course in philosophy of science. On the other hand, there are plenty of exciting examples that can (and sometimes did) lever lecturers and students into a broader interest in HPS, such as the question whether staff and students need to 'stay objective' or can make normative statements concerning the biodiversity loss and the global climate crisis. How to tap into this potential motivation for HPS education in the geosciences?

\section{A practical pedagogy: understanding science, philosophy and history}

Parallel developments in history of science and in philosophy of science in the past decades have made both fields more accessible and of more immediate interest to science students and scientists. One such development is the Philosophy of Science in Practice. A highly relevant notion is scientific understanding, which, as opposed to scientific explanation, refers to epistemic skills gained by an actor, by engaging with a theory, sensory experiences and intervention (de Regt, 2017). In parallel, embodied understanding has also been studied in psychology and neurology, in order to unravel the links between body, emotion, sense of self and explanation of the world (Darling-Hammond et al., 2020). This resonates strongly with the emphasis on fieldwork in geoscientific curricula (Mogk \& Goodwin, 2012) and practicals with numerical modelling (Kelly \& Licona, 2018).

A parallel development is that of conceptual history of knowledge mentioned earlier (Daston \& Galison, 2007; Koselleck, 2002). The German term Begriffsgeschichte adds a layer of meaning of science-in-practice to the English term conceptual history, as the German Begriff (and related Dutch begrip) means not only a concept that represents something, but also means the understanding that comes with the representation or imagination of that something.

Both practical turns link to effective learning. Students learn much, perhaps most, about science by doing. It is in the practice of science where science is taught most memorably. Likewise, philosophy and history of science becomes most meaningful when it is practiced, whether in the classroom, in the laboratory or in fieldwork. 
Implications for educating HPS to earth science students are that the HPS elements need to be solidly connected to earth science, and that HPS lecturers need to have sufficient understanding of several geoscience disciplines beyond the classic topics emphasised in the HPS literature.

\section{A baby step: a case of practical Philosophy of Earth Science education}

Following the political outcry after a notorious case of fraude in social science in the Netherlands, Utrecht University decided in 2011 that all curricula should have a course that deals with basic concepts and societal context. As a result, I have been allowed to teach a minor but compulsory course in the first year of the bachelor of earth science program, named 'Time and causality' (see online supplement for study guide). The course is four study credits (European Credit Transfer and Accumulation System), meaning a total student time investment of 1.5 days per week over a period of 9 weeks. Two thematic threads are woven together, supported by a small set of simplified concepts and graphic scaffolds. The first thread is how earth (system) science works, in terms of method and interdisciplinarity. The focus is on philosophy for science in a simplified practice. The second thread is how it interacts with society. For such interaction to be successful, students need at least to be able to communicate the essence of a scientific study in simple terms. They also need to be able to articulate how science works at a level of detail that suits the audience, whether pupils, public or policymakers. An overview of the lecture subjects and learning activities elaborated below is given in Table 1.

To begin, I use a simple demonstration experiment to model the reasoning skills of inference and the use of the hypothetico-deductive method, the 'empirical cycle', as a scaffold for experiment design and hypothesis testing. This experiment is the same that I conduct with primary school pupils in summerschools and STEM lessons (Kleinhans et al., 2015): a simple fan-shaped deposit which forms as water from a garden hose flows onto a pile of sand. Such alluvial fans are distinct and important landforms on Earth and on Mars. By changing one variable or condition at the same time, hypotheses can be tested by comparison to the control experiment without change. To prepare, a series of practical exercises in analysis of the structure of ten scientific publications of their own teaching staff. These papers were selected for their clear writing, are well spread over the disciplines taught in the curriculum and have examples with field data, experimentation and numerical modelling. Students discover that most papers have been written up in the form of the empirical cycle, which leads to discussion about practical and historical reasons for this.

The methods of fieldwork, physical experiments and numerical modelling are then compared in terms of control, materiality, representation and underdetermination (Bokulich \& Oreskes, 2017; Kleinhans et al., 2010; Morgan, 2003). In a natural way this can be used for discussion of why certain observations are made in fieldwork and why other sense data is ignored, how hypotheses of past and present phenomena are underdetermined by evidence, what the theory-ladenness is of the observations and how the steps in data reduction mean idealization. This, in turn, 


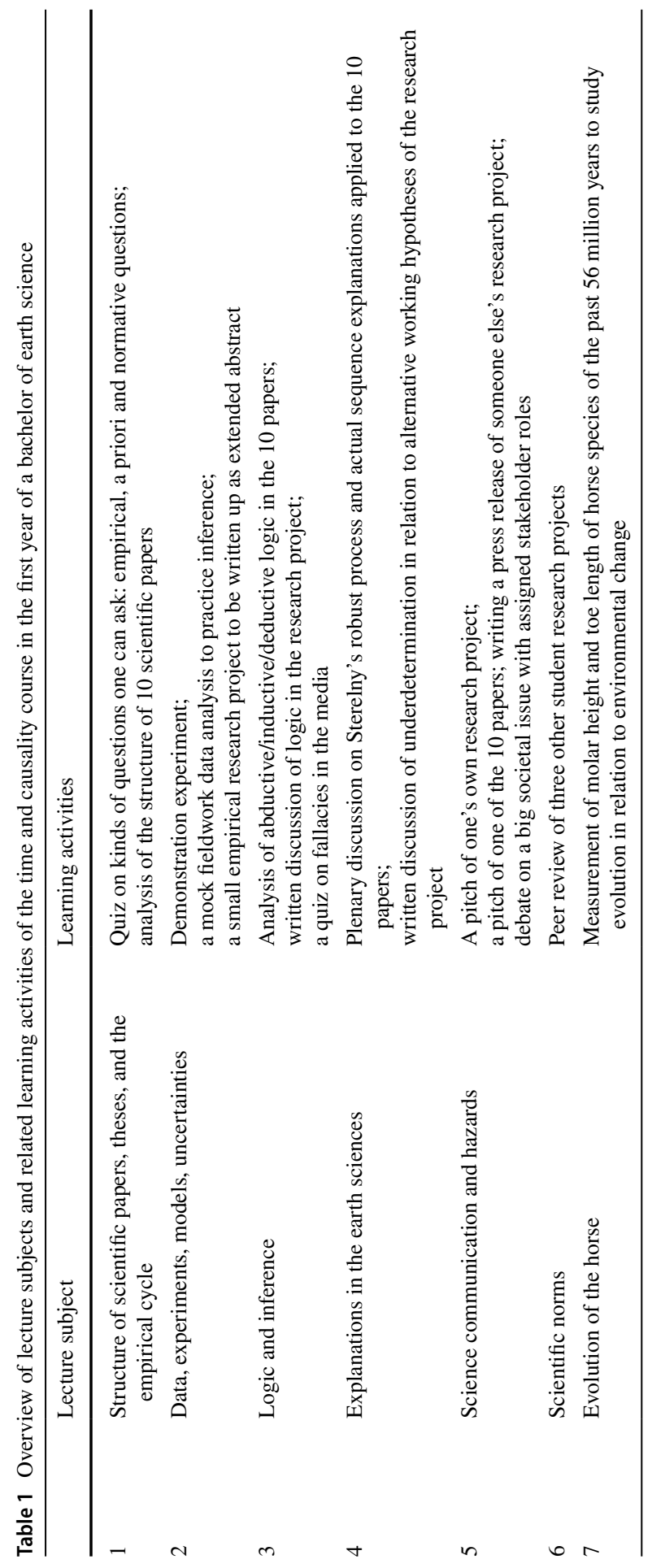


leads to recognition how explanations in earth science are built on logical inferences and on results of complementary methodologies.

Students then have to conduct a simple experiment at home. Any experiment with a control is allowed, and humor is encouraged. One student tested Murphy's 'law' by dropping 50 peanut butter jelly sandwiches from the third floor into the garden. Murphy's law states that anything that can go wrong, will go wrong. In the sandwich experiment, the implication would be that most sandwiches fall on the buttered side, whereas if the falling is a random process then the implication is that about half the sandwiches fall on the buttered side. They have to write up their project in the classic order of introduction and alternative working hypothesis (Chamberlin, 1890), methods, results, discussion and conclusions in the format of the two-page extended abstract of the Lunar and Planetary Science Conference. They then discover that the empirical cycle is a gross simplification of the practice of experimental science, but has its use in communication within science. Furthermore they have to review three other abstracts and then discover that some of their comments on others also apply to their own work. Both the reviews and the revised abstract are graded.

The possibilities and pitfalls of causation from statistical correlation are illustrated during the course by grouping students for their practicals by something personal, such as birth date and constellation, parental province or date of subscription to this bachelor, and then demonstrate statistical relations with their presence and performance. Well-known examples of such relations are shown, such as horoscopes for top sporters and Noble prize winners. Surprisingly, student absence showed a significant relation with the parental province grouping in one year due to the rapid spreading of influenza in those regions with more convivial carnival festivities in spring. The students are assigned (by an administrator, not by me, for privacy reasons) to the groups without their knowledge and are surprised with the results a lecture late in the course. Basic causation is further discussed in class with examples of mechanistic and probabilistic studies of river meandering, and how these studies interact through discussion and cross-references. This would in principle be a great starting point for philosophical reflection on causality (Illari \& Russo, 2014) but in the first year of the bachelor the students have hardly had any experience with data analyses and have had no course in statistics yet, let alone an opportunity to reflect on the differences between causation taught in the physics course and that conducted in geostatistics.

A two-page reflective essay on two philosophical aspects of their own abstract is also graded. To prepare, an early practical is a discussion about propositions. First, fallacies are studied in hypothetical examples and real texts, including extensive statements by politicians about climate change. The students have to submit a few examples the news media, but are told to avoid certain well-known politicians who excel in fallacies, which stimulates students to study their clear examples (reverse psychology). Second, a series of propositions are simplistically classified into empirical, normative and a priori statements. Discussion is stimulated by red herrings in the examples, and some statements are included that can be construed as being both empirical and normative, and have unstated background assumptions. For example, "The first year of the Earth Science bachelor is far too easy", can empirically be tested by comparison to other curricula but is also an imprecise normative statement. 
All this serves to give a taste of the need to formulate more precisely, of the limits of science and of the question of what can be studied empirically.

The third kind of analysis on the logic in scientific papers is to identify whether it is deductive, inductive or abductive (Baker, 1996; Kleinhans et al., 2010). A scaffold shows graphically, as a triangle diagram, the relation between the three at the level of simplification required for first year students: generalisations are induced from causes and effects, effects are deduced from causes and laws, or generalisations, and past causes are abduced from effects and generalisations or laws. The last form is largely unknown amongst scientists, but is applied frequently in geological reconstruction from the preserved rock record of conditions and phenomena in deep time (Inkpen, 2008). The exercise makes them realise the often unstated assumptions and laws, generalisations and the background theories and models in geoscientific studies. In turn, this leads to a brief discussion of what a law is and what the importance is of physical reductionism in the geosciences. The basic differences between induction, deduction and abduction are sought and recognised in the ten papers as an exercise and in the student's own abstract, and discussed in the two-page philosophical writing assignment for a partial grade. In this essay, the students must also analyse whether how their hypothesis selection is underdetermined by the collected data, which they find quite challenging as their answers usually amount to a need to collect more data. The compulsory reading material consists of Kleinhans et al. (2010), an E-book (www.understandingscience.org), and the lecture slides. The students are encouraged to read the sources linked on the slides (papers and other resources) but only some do so. In past years I experimented with having students read some philosophical texts but they rarely did and had difficulty with the terminology.

Two other useful forms of logical reasoning are very briefly introduced. Functional reasoning is contrasted with teleological reasoning. Teleological explanations are at the heart of actions of humans on the planet. For example, the explanation of the existence of dikes on the river delta plain that my university is located on, is that they are intended to prevent future flooding. Many hazards and 'natural' disasters came about from human interference on the planet. For example, a historic flood in the Netherlands in 1421 and the flooding of New Orleans following hurricane Katrina in 2005 are in part caused by the unimpeded subsidence due to lack of natural river sedimentation behind the dikes. A helpful distinction between two kinds of explanations is that of Sterelny (1996, also see Kleinhans et al., 2005) is that of robust-process explanations, which focus on generic causes such as the detrimental effects of embankment in many rivers and deltas worldwide, and actual-sequence explanations, which are the exact sequence of events that led to some effect, such as the flooding disasters in the examples above. This distinction is helpful for the students in that it shows the complementary epistemic value of reconstructions of past events (and past human intentions) and that of mechanistic research by modelling and experimentation. I also see such conceptual developments for students as a first step in the identification and analysis of geoscientific methods, about which every large conference sees poorly conducted discussion of the epistemic value of, for example, field data (a citation best kept anonymous: "the data speaks straight from reality and your model is but fiction") versus physics-based models (ibid.: "this is well-proven physics, while your data can have errors"). 
Ubiquitous biological interactions with earth systems make functional explanations relevant in many ways. A practical with fossil bones of horse species that evolved since 56 million years ago teaches the students that there are regularities in evolution related to functional explanations, but no final aim of evolution. Moreover, the evolution of the horses is intricately linked to a change in climate and in vegetation. This not only illustrates the logic of abductive inference from the preserved fossils and their context, but also shows how certain evolutionary trends develop through interaction between species. The horses increased in body size through time, as many animals do, but particularly get longer legs as a survival trait in response to an expansion of grasslands. Furthermore, their teeth grew longer and harder to deal with the grasses, which, in turn, built in more silica in the competition with grazing animals in general. The example of horse evolution is attractive, because it shows the interaction between climate, species and evolution, and because it is about an animal that is still alive, allowing for personal observations of behaviour.

Clear communication is a basic but difficult skill needed in science, education, science communication and debate of societally relevant issues. With the logical reasoning skills, this links the two thematic course threads of science and society. Students begin by pitching the main message of one of the ten papers, and as several pitches for the same paper are compared, the properties of effective pitches are discussed. Later in the course, they also have to pitch their idea for their own experiment. After studying some press releases and newspaper articles about scientific papers, they have to write a press release for another student's experiment for a broad audience. The importance of the audience is explained with the classic sender-channel-receiver model, where interests of the receiver determine their willingness to pay attention and to have faith in the sender. The structure of the press release is very different from that of a scientific paper but similar to a 'high impact' paper, with the main, catchy message and implications first and the methods last. This exercise is not graded but is intended to improve clarity of the graded abstract.

A parliamentary debate is then held in 10-15 groups of about 10 students each around a major geoscientific issue, such as gas extraction-induced earthquakes in the north of the Netherlands, or effects of palm oil plantations on biodiversity and climate. Students love to debate hot societal issues, and the common tendency to favour presentation style over supporting evidence for arguments can be used to leverage development of metacognitive skills (Scherer et al., 2017). Students in each group are assigned specific, straightforward stakeholder roles, such as politician, NGO, company, and scientist. The 'scientists' usually find that they can only play a minor role because much of the debate is about political choice rather than knowledge and system understanding. Students in the role of expert scientist also struggle with the fact that 'scientific facts' unavoidably have ethical implications (Gailbraith, 2021). The students never accused their fellow students in the role of scientists of plagiarism or fraud, despite attention to definitions, examples and codes of conduct for scientists in the preceding lecture and critical reflection on such codes would require more experience and bespoke learning activities. I add a secret temptation to violate the code of scientific conduct: one of the commercial parties in each group is given two bars of chocolate for bribery. Once, two 'scientists' were successfully bribed to argue with bias, which led to rambunctious and educational discussion 
about the ethics of science and the ethics of politics. This kind of learning activity motivates the first-year students much more than relevant HPS reading material and the bribing can be seen as educational experimenting in a safe environment.

The position of this course in the first year is unfortunate, because the students have hardly developed a knowledge base and basic laboratory and data skills, and have not yet conducted a fieldwork study. As a result, the connections between HPS topics and their experience with the practice of earth science are hardly beyond what can be accomplished with any highschool graduate with some sort of STEM profile. (On the other hand, the eight teaching assistants for the practicals gain much understanding beyond what they learned in their first year by their teaching of the practicals.) Other courses in the first year are about inner Earth, the Earth's surface, Earth's development through time (including evolution of species), chemistry, mechanics and mathematics, and mapping in the field (France or Spain). Recommended thematic study paths link related courses within disciplines of the earth sciences. The intended learning outcomes and contents of the Time and Causality course are communicated to other lecturers before the fieldworks commence every year, but are largely ignored and forgotten as also evidenced by students in my third year thematic course where the majority of $\sim 250$ students over the past 10 years claimed not to have heard of the empirical cycle and not to have written any report in that form, ever. In the second and third year of the bachelor, the students have no major compulsory courses together but only electives, limiting possibilities and effectiveness of collective academic skill and HPS training. Yet, all students need these at the end of the bachelor when they have to write a bachelor thesis. Explaining that the Time and Causality course is the first step towards this, only helps about half the students to be motivated for the course activities, as is obvious from the student evaluation. While evaluations conducted immediately after the course have very limited use, they indicate student motivation. Communication with society is even further distanced from what students are occupied with. The need for communication arises out of the hope to have impact with science in society as voiced in the DORA declaration, and it is a requirement in European grant agreements. However, as most students in the Netherlands leave university only after obtaining a masters degree, part of the learning activities in the first year in the bachelor are premature. (On the other hand, the older teaching assistants understand the use and value the skills developed in the course.)

\section{A wish list for history and philosophy of earth science education}

A practically feasible approach would be to implement specific HPS elements with selected background reading and discussion as part of major compulsory courses throughout the bachelor curriculum where they are appropriate. These elements should be reactivated in some subsequent courses. HPS themes can thus be 'spotwelded' into the earth science curriculum. A more formal overview of main themes could then be provided in a capstone course, compulsory for all students, HPS topics are drawn together under headers such as epistemology, metaphysics and perspectives, and ethics for science and society. The capstone course could be combined 
with essential professional skills (e.g. writing, open science, scientific integrity) needed before finishing the Bachelor and before writing the BSc-Thesis.

In the capstone course, a number of themes from HPS elements in the preceding courses can be dealt with in much more depth and reading material than in the first year, such as inference, the induction problem, and causality. Specific models of causality are interesting to provide, because they are easily recognizable in the practice of earth science, such as the model that many, if not all, causes are INUS (Insufficient but Non-redundant part of Unnecessary but Sufficient) causes and differencemakers (e.g. Illari \& Russo, 2014). Classifications of rocks and species can lead to a large number of questions about natural kinds, and the definition and traces of life.

Past controversies are carried along in misconceptions that students maintained or developed in secondary education (Francek, 2013), meaning that they can be used to attract the attention in class and develop awareness. Plate tectonics, the classic exemplar of earth science synthesis and controversy, has it use in the first year but showing students how geoscientific disagreements are resolved in daily practice requires modern examples from several disciplines (Dodick \& Dolphin, 2013).

System science is a much more general synthesis than plate tectonics and provides ample opportunity for connection to HPS themes of representation, causality, complexity, historical developments and simulation models of earth systems (e.g. Gramelsberger et al., 2020). Other fields demonstrate that undergraduate students can grasp the complex syntheses of systems sciences (Batzri et al., 2015; Scherer et al., 2017; Verhoeff et al., 2018). Stillings (2012) proposes that all kinds of systems concepts should be introduced, cross-referenced, and reinforced in multiple courses across the curriculum. An added layer of HPS can help clarify what systems entail (e.g. Ladyman et al., 2013). Some practice in clear and simple communication is also required to be able to work in the interdisciplinary context that system science often has.

The value for society and the values of science could be developed, employing experiences in sustainability science, on uncomfortable themes of great interest to geoscience such as the implications of geo-engineering (Gailbraith, 2021), and the proofs unearthed by Supran and Oreskes (2017) of how oil companies, for which geology has long been the academic training, misled the public for decades. Moreover, students need HPS abilities to distinguish fake from science, to analyse the arguments in conspiracy theories and scientific theories, and to explain this convincingly in a role as expert to policymakers who labour under a high lobby pressure from all manner and kind of interested societal parties.

All the above is interesting to geoscience undergraduates after they have hammered out some of their own epistemic practices. For example, it only makes sense to reflect critically on the justification and complementarity of mechanistic and probabilistic causation after one has gained some understanding of both. Scientific understanding may come with theory and experience. Likewise, experience of the expert role that graduates may take up some time can be gained in learning activities such as well-prepared debate and reflection, on top of which a critical discussion of the code of scientific conduct can be built, and reflecting on the possible societal consequences of scientific research. As a result, students may be better equiped to learn and to apply the codes, protocols and conventions 
of their field-or to deviate from them with reason. However, teaching HPS to science students is not intended to teach them how to do HPS. Some students may later turn to the humanities in a master program, but all scientists need knowledge and skills best developed in HPS education to become better scientists (also see Grüne-Yanoff, 2014), whether in academia or in some role in society. Of course, this requires that philosophers teach not the basics and history of philosophy of science, but the basics of philosophical and historical reflection on science in practice with the betterment of the undergraduates as future scientists and experts in mind. One might even cheekily suggest that this could well be the main purpose of academic science education.

Acknowledgements This paper was written as part of a fellowship at the Netherlands Institute for Advanced Study in the Humanities and Social Sciences (NIAS-KNAW), Amsterdam, The Netherlands. Two reviewers provided helpful and constructive comments on an earlier draft. Wilma Wessels designed the horse fossil practical and many teaching assistants contributed to the described course with improvements. Joeri Witteveen and Jelmer Cleveringa are thanked for insightful discussion.

\section{Declarations}

Conflict of interest I declare to have no conflict of interest.

Open Access This article is licensed under a Creative Commons Attribution 4.0 International License, which permits use, sharing, adaptation, distribution and reproduction in any medium or format, as long as you give appropriate credit to the original author(s) and the source, provide a link to the Creative Commons licence, and indicate if changes were made. The images or other third party material in this article are included in the article's Creative Commons licence, unless indicated otherwise in a credit line to the material. If material is not included in the article's Creative Commons licence and your intended use is not permitted by statutory regulation or exceeds the permitted use, you will need to obtain permission directly from the copyright holder. To view a copy of this licence, visit http://creativecommons.org/licen ses/by/4.0/.

\section{References}

Baker, V. R. (1996). Hypotheses and geomorphological reasoning. In B. L. Rhoads \& C. E. Thorn (Eds.), The scientific nature of geomorphology. Wiley, pp. 57-86.

Baker, V. R. (1998). Catastrophism and uniformitarianism: Logical roots and current relevance in geology. In D. J. Blundell \& A. C. Scott (Eds.), Lyell: The past is the key to the present. Geological society (vol. 143, pp. 171-182), Special Publications.

Batzri, O., Ben ZviAssaraf, O., Cohen, C., \& Orion, N. (2015). Understanding the earth systems: Expressions of dynamic and cyclic thinking among university students. Journal of Science Education and Technology, 2015(24), 761-775. https://doi.org/10.1007/S10956-015-9562-8

Bierman, P. (2021). A department terminated. Science, 371(6527), 434.

Bokulich, A., \& Oreskes, N. (2017). Models in geosciences. Ch. 41. In L. Magnani \& T. Bertolotti (Eds.), Handbook of model-based science (pp. 891-911). Springer.

Boon, M., \& van Baalen, S. (2019). Epistemology for interdisciplinary research - shifting philosophical paradigms of science. European Journal for Philosophy of Science, 9, 16. https://doi.org/10.1007/ s13194-018-0242-4.

Chamberlin, T. C. (1890). The method of multiple working hypotheses. Science, 15, 92-96.

Cleland, C. E. (2001). Historical science, experimental science, and the scientific method. Geology, 29(11), 987-990. 
Currie, A. (2018). Rock, bone and ruin; an optimist's guide to the historical sciences. The MIT Press.

Darling-Hammond, L., Flook, L., Cook-Harvey, C., Barron, B., \& Osher, D. (2020). Implications for educational practice of the science of learning and development. Applied Developmental Science, 24(2), 97-140. https://doi.org/10.1080/10888691.2018.1537791

Daston, L. and Galison, P. (2007). Objectivity. Zone Books, 501 pages.

de Regt, H. W. (2017). Understanding scientific understanding. Oxford University Press, Oxford Studies in Philosophy of Science, pp. 301.

Dodick, J., \& Dolphin, G. (2013). Geological controversies: A role for history and philosophy of science in earth science education, education. In V. R. Baker (Ed.), Rethinking the fabric of geology: Geological society of America special paper (vol. 502, p. 165-182). https://doi.org/10.1130/2013. 2502(10)

Eflin, J. T., Glennan, S., \& Reisch, G. (1999). the nature of science: A perspective from the philosophy of science. Journal of Research in Science Teaching, 36(1), 107-116.

Francek, M. (2013). A Compilation and Review of over 500 Geoscience Misconceptions. International Journal of Science Education, 35(1), 31-64. https://doi.org/10.1080/09500693.2012.736644

Gailbraith, J. (2021). Values in early-stage climate engineering: The ethical implications of "doing the research.” Studies in History and Philosophy of Science Part A, 86, 103-113. https://doi.org/10. 1016/j.shpsa.2021.01.009

Gill, J. C., \& Smith, M. (Eds) (2021). Geosciences and the sustainable development goals. Springer Nature, 474 p. https://doi.org/10.1007/978-3-030-38815-7.

Gramelsberger, G., Lenhard, J., \& Parker, W. S. (2020). Philosophical perspectives on Earth system modeling: Truth, adequacy, and understanding. Journal of Advances in Modeling Earth Systems, 12, e2019MS001720. https://doi.org/10.1029/2019MS001720

Grüne-Yanoff, T. (2014). Teaching philosophy of science to scientists: Why, what and how. European Journal for Philosophy of Science, 4, 115-134. https://doi.org/10.1007/s13194-013-0078-x

Holbrook, J., \& Rannikmae, M. (2007). The Nature of Science Education for Enhancing Scientific Literacy. International Journal of Science Education, 29(11), 1347-1362. https://doi.org/10.1080/09500 690601007549

Illari, P., \& Russo, F. (2014). Causality: Philosophical theory meets scientific practice. Oxford University Press.

Inkpen, R. J. (2008). Explaining the Past in the Geosciences. Philosophia, 36, 495-507.

Kelly, G. J., \& Licona, P. (2018). Epistemic practices and science education. Chapter 5. In M. R. Matthews (Ed.), History, philosophy and science teaching, new perspectives. Springer.

Kleinhans, M. G., Buskes, C. J. J., \& De Regt, H. W. (2005). Terra Incognita: Explanation and Reductionism in Earth Science. International Studies in the Philosophy of Science, 19(3), 289-317. https://doi.org/10.1080/02698590500462356

Kleinhans, M. G., Bierkens, M. F. P., \& van der Perk, M. (2010). On the use of laboratory experimentation: "Hydrologists, bring out shovels and garden hoses and hit the dirt". Hydrology and Earth System Sciences, 14, 369-382. https://doi.org/10.5194/hess-14-369-2010

Kleinhans, M. G., Verkade, A. J., van Wessel, T., Bastings, M. A. S., Marra, W. A., van Gog, T., van Westrenen, W., \& Reichwein, M. (2015). Moon, Mars and Mundus: Primary school children discover the nature and science of planet Earth from experimentation and extra-terrestrial perspectives. Netherlands Journal of Geoscience, 95(2), 203-214.

Koselleck, R. (2002). Social history and conceptual history, Ch. 2 in The practice of conceptual history. Stanford University Press.

Ladyman, J., Lambert, J., \& Wiesner, K. (2013). What is a complex system? European Journal for Philosophy of Science, 3, 33-67.

Machamer, P. (1998). Philosophy of science: An overview for educators. Science and Education, 7, 1-11.

Matthews, M. R. (Ed) (2018). History, Philosophy and Science Teaching: new perspectives. Springer Nature, 326 p. https://doi.org/10.1007/978-3-319-62616-1.

Mogk, D. W., \& Goodwin, C. (2012). Learning in the field: Synthesis of research on thinking and learning in the geosciences. Geological Society of America Special Papers, 486, 131-163. https://doi.org/ $10.1130 / 2012.2486(24)$

Morgan, M. S. (2003). Experiments without material intervention. Model experiments, virtual experiments, and virtually experiments. Ch. 11. In H. Radder, The philosophy of scientific experimentation (pp. 216-235). University of Pittsburgh Press.

Parker, W. S. (2014). Simulation and Understanding in the Study of Weather and Climate. Perspectives on Science, 22(3), 336-356. https://doi.org/10.1162/POSC_a_00137 
Rappaport, R. (2008). The Earth sciences. Cambridge Encyclopedia of History of Science, chapter 8.

Resnik, D. B., \& Elliott, K. C. (2019). Value-entanglement and the integrity of scientific research. Studies in History and Philosophy of Science, 75, 1-11. https://doi.org/10.1016/j.shpsa.2018.12.011

Rudwick, M. J. S. (2014). Earth's deep history; how it was discovered and why it matters. The University of Chicago Press.

Schellnhuber, H. J. (1999). 'Earth system' analysis and the second Copernican revolution. Nature, 204, C19-C23.

Scherer, H. H., Holder, L., \& Herbert, B. (2017). Student learning of complex earth systems: Conceptual frameworks of earth systems and instructional design. Journal of Geoscience Education, 65(4), 473-489. https://doi.org/10.5408/16-208.1.

Steffen, W., Richardson, K., Rockström, J., Schellnhuber, H. K., Dube, O. P., Dutreuil, S., Lenton, T. M., \& Lubchenco, J. (2020). The emergence and evolution of Earth System Science. Nature Reviews, 1, 54-63.

Sterelny, K. (1996). Explanatory pluralism in evolutionary biology. Biology and Philosophy, 11, 193-214.

Stewart, I. S., \& Lewis, D. (2017). Communicating contested geoscience to the public: Moving from 'matters of fact' to 'matters of concern.' Earth-Science Reviews, 174(2017), 122-133. https://doi. org/10.1016/j.earscirev.2017.09.003

Stillings, N. (2012). Complex systems in the geosciences and in geoscience learning. In K. A. Kastens \& C. A. Manduca (Eds.), Earth and mind II: A synthesis of research on thinking and learning in the geosciences: Geological society of America special paper (vol. 486, p. 97-111). https://doi.org/10. 1130/2012.2486(17).

Supran, G., \& Oreskes, N. (2017). Assessing ExxonMobil's climate change communications (19772014). Environmental Research Letters, 12, 084019. https://doi.org/10.1088/1748-9326/aa815f

Verhoeff, R. P., Knipples, M.-C.P.J., Gilissen, M. G. R., \& Boersma, K. T. (2018). The theoretical nature of systems thinking. Perspectives on systems thinking in biology education. Frontiers Education, 3, 40. https://doi.org/10.3389/feduc.2018.00040.

Publisher's note Springer Nature remains neutral with regard to jurisdictional claims in published maps and institutional affiliations. 